\title{
Direct innominate artery cannulation for selective antegrade cerebral perfusion during deep hypothermic circulatory arrest in aortic surgery
}

\author{
Vinay Garg, BHSc, ${ }^{a}$ Dimitrios N. Tsirigotis, MD, PhD, ${ }^{\mathrm{a}}$ Jeff Dickson, MD,${ }^{\mathrm{b}}$ Constantine Dalamagas, CPC, \\ David A. Latter, MD, ${ }^{a}$ Subodh Verma, MD, PhD, ${ }^{a}$ and Mark D. Peterson, MD, $\mathrm{PhD}^{\mathrm{a}}$
}

\begin{abstract}
Objective: To demonstrate a novel, reproducible, and effective method of direct innominate artery cannulation using a $14 \mathrm{~F}$ pediatric venous cannula to establish antegrade cerebral protection (ACP) in patients undergoing aortic surgery that requires an open distal anastomosis or hemiarch replacement.
\end{abstract}

\begin{abstract}
Methods: We reviewed prospectively gathered data on all patients who had undergone replacement of the ascending aorta or hemiarch with an open distal anastomosis using deep hypothermic circulatory arrest and direct innominate artery cannulation with a $14 \mathrm{~F}$ pediatric venous cannula at our institution. After central cannulation and cooling to $25^{\circ} \mathrm{C}$ to $28^{\circ} \mathrm{C}$, all patients had ACP initiated by way of a direct innominate cannula placed over a guidewire.
\end{abstract}

Results: Fifty patients underwent direct innominate artery cannulation with our technique from 2010 to 2012. The operative mortality was $2 \%(n=1)$, and the rates of neurologic morbidity were acceptable and similar to those with other methods of ACP delivery: stroke $(2 \%, n=1)$, seizure $(0 \%, n=0)$, and delirium $(18 \%, n=9)$. The mean operative time was $31 \pm 9,19 \pm 5,100 \pm 39,141 \pm 39$, and $259 \pm 63$ minutes for cooling, circulatory arrest, crossclamp, cardiopulmonary bypass, and total operative time, respectively. No local or arterial complications were observed.

Conclusions: Direct cannulation of the innominate artery using a 14F pediatric venous cannula is a simple, reproducible, safe, and effective technique for establishing ACP in patients undergoing aortic surgery that requires an open distal anastomosis or hemiarch replacement. This technique avoids the additional time and potential local complications associated with other established methods for delivering ACP, such as axillary cannulation. (J Thorac Cardiovasc Surg 2014;148:2920-4)

See related commentary on pages 2924-6.

Video clip is available online.
Surgery involving the ascending aorta and proximal aortic arch often requires a period of circulatory arrest, with the attendant increased risk of neurologic injury. Antegrade cerebral perfusion (ACP) is thought to minimize the ischemic

From the Divisions of Cardiac Surgery, ${ }^{\mathrm{a}}$ Anesthesiology, ${ }^{\mathrm{b}}$ and Cardiac Perfusion, ${ }^{\mathrm{c}}$ St Michael's Hospital, University of Toronto, Toronto, Ontario, Canada.

Disclosures: Authors have nothing to disclose with regard to commercial support.

Read at the 94th Annual Meeting of The American Association for Thoracic Surgery, Toronto, Ontario, Canada, April 26-30, 2014.

Received for publication April 5, 2014; revisions received June 27, 2014; accepted for publication July 2, 2014; available ahead of print Aug 27, 2014.

Address for reprints: Mark D. Peterson, MD, PhD, Division of Cardiac Surgery, Suite-8-003H, Bond Wing, St Michael's Hospital, 30 Bond St, Toronto, ON M5B 1W8, Canada (E-mail: petersonm@smh.ca).

$0022-5223 / \$ 36.00$

Copyright $\odot 2014$ by The American Association for Thoracic Surgery

http://dx.doi.org/10.1016/j.jtcvs.2014.07.021 sequelae of deep hypothermic circulatory arrest (DHCA) on the brain. ACP by cannulation of the axillary artery has been established as both a safe and an effective method. ${ }^{1}$ However, dissection of the axillary artery requires additional time and introduces potential complications such as brachial plexus injury, seromas, and limb ischemia. ${ }^{2,3}$ To avoid these complications and streamline operations requiring brief periods of circulatory arrest, we have used a strategy of direct cannulation of the innominate artery for ACP. We report the use of a $14 \mathrm{~F}$ pediatric venous catheter to cannulate the innominate artery and demonstrate that innominate artery cannulation is a safe and effective technique for establishing $\mathrm{ACP}$ in patients undergoing DHCA for ascending aortic and proximal aortic arch surgery.

\section{METHODS \\ Patients}

From October 2010 to December 2012, 50 patients were treated surgically with replacement of the ascending aorta using an open distal anastomosis or hemiarch replacement with DHCA $\left(25^{\circ} \mathrm{C}-26^{\circ} \mathrm{C}\right)$. The patients' baseline demographic characteristics are listed in Table 1, and the type of aortic operation is listed in Table 2. Patients undergoing emergency or urgent surgery, including surgery for acute aortic dissection, and patients requiring total arch reconstruction were excluded. Our 


\section{Abbreviations and Acronyms}

$\mathrm{ACP}=$ antegrade cerebral perfusion

$\mathrm{CPB}=$ cardiopulmonary bypass

DHCA $=$ deep hypothermic circulatory arrest

ICU = intensive care unit

institutional research ethics board approved the study and did not require that we obtain individual patient consent.

\section{Operative Technique}

After median sternotomy and systemic heparinization, the distal aneurysmal ascending aorta was cannulated using a standard 7- or 8-mm arterial cannula. The right atrium was cannulated with a 2 -stage venous cannula, a retrograde cardioplegia catheter was placed into the coronary sinus, and cardiopulmonary bypass (CPB) and systemic cooling was initiated. During the cooling phase, we mobilized the ascending aorta and proximal arch, isolated the innominate vein, and gently dissected and mobilized the base of the innominate artery. Two purse-string sutures of 4-0 RB1 polypropylene were placed on the anterior wall of the proximal innominate artery (Figure 1, A). Once the systemic core temperature was $<28^{\circ} \mathrm{C}$, we cannulated the innominate artery with a 0.035 -in. J wire, sequentially dilated the artery with $8 / 10 \mathrm{~F}$ and $12 / 14 \mathrm{~F}$ dilators (Medtronic, Inc, Minneapolis, Minn), and then inserted a $14 \mathrm{~F}$ pediatric venous cannula (Terumo, Somerset, $\mathrm{NJ}$ ) over a guidewire. The period of circulatory arrest with ACP was initiated by clamping the base of the innominate artery and connecting the afferent limb of the $\mathrm{CPB}$ circuit to the cannula using a $3 / 8$ to $1 / 4$ connector. Cold blood $\left(22^{\circ} \mathrm{C}\right)$ was delivered at a flow rate of 10 to $12 \mathrm{~mL} /$ $\mathrm{kg}$ to achieve a right brachial pressure of 50 to $70 \mathrm{~mm} \mathrm{Hg}$. The distal anastomosis was performed as either a beveled hemiarch or an end-to-end anastomosis using a Gelweave woven polyester graft with an 8-mm side limb (Vascutek Terumo, Renfrewshire, Scotland; Figure 1, B). Once the distal anastomosis was completed, the ACP was discontinued, the aortic line was connected to the side limb of the graft, and full CPB and rewarming was resumed and the proximal reconstruction completed (Figure 1,C). The technique has been summarized in a brief video (Video E1).

\section{RESULTS}

The pre- and intraoperative characteristics are summarized in Tables 1 and 2. The mean patient age in the present study was $60 \pm 10$ years. The baseline characteristics of our patients were similar to those of patients undergoing proximal aortic surgery reported by other centers. ${ }^{4,5}$ A breakdown of the aortic procedures performed in the present study is listed in Table 2. The mean total operative time was $259 \pm 63$ minutes, with a mean circulatory arrest time of $19 \pm 5$ minutes, and the mean total CPB duration was $141 \pm 39$ minutes.

The postoperative outcomes of patients are summarized in Table 3. The perioperative mortality was $2 \%$. The 1 death in our series was attributable to the patient's difficulty in weaning from the ventilator in the intensive care unit (ICU) secondary to pre-existing chronic obstructive pulmonary disease. The patient subsequently developed Citrobacter koseri sepsis in the ICU and died on postoperative day 9 . The median ICU stay was $23 \pm 95$ hours, with a median postoperative hospital stay of $6 \pm 8$ days. One patient experienced a postoperative stroke $(2 \%)$. This patient had undergone a Bentall plus hemiarch procedure and developed moderate dysarthria and expressive aphasia on postoperative day 1. His modified National Institutes of Health score was 5. A transesophageal echocardiogram did not show evidence of thrombus, and the computed tomography findings were negative both in-hospital and at the 2-month follow-up point. The associated neurologic deficits had completely resolved at the 2-month follow-up visit.

\section{DISCUSSION}

Cerebral protection strategies have evolved over the years to reduce neurologic complications during aortic arch surgery. Initially, DHCA alone was the primary method of neuroprotection, followed by the introduction of retrograde cerebral perfusion as a technique to improve the neuroprotection during DHCA; however, studies were unable to clearly demonstrate effective metabolic support or improved neurologic outcomes. ${ }^{6-8}$ Sabik and colleagues ${ }^{2,3}$ introduced axillary artery cannulation, allowing for ACP. Research comparing ACP and retrograde cerebral perfusion has shown that ACP provides uniform brain perfusion, allows more surgical time for complex aortic procedures, and provides more optimal cerebral protection. ${ }^{9-12}$ Furthermore, Halkos and colleagues ${ }^{13}$ demonstrated that ACP was associated with shorter ICU and ventilator times and fewer renal and pulmonary complications. Thus, ACP, most often delivered by the axillary artery, has become the standard method of neuroprotection for aortic arch operations. Axillary artery cannulation provides excellent unilateral cerebral brain perfusion during DHCA; however, it is time consuming and is associated with a small, but not insignificant, risk of brachial plexus injury and a relatively high incidence of seroma formation. ${ }^{10}$

TABLE 1. Preoperative patient characteristics

\begin{tabular}{lc}
\hline \multicolumn{1}{c}{ Preoperative characteristics } & Value \\
\hline Age (y) & $60 \pm 10$ \\
Male sex & $38(76)$ \\
NYHA class $\geq 3$ & $8(16)$ \\
Diabetes mellitus & $5(10)$ \\
Hypertension & $36(72)$ \\
Hypercholesterolemia & $22(44)$ \\
Family history of heart or aortic disease & $6(12)$ \\
Smoking history & $27(54)$ \\
COPD & $4(8)$ \\
Peripheral vascular disease & $1(2)$ \\
Renal failure & $2(4)$ \\
Stroke history & 0 \\
BSA (cm ${ }^{2}$ ) & $1.98 \pm 0.23$ \\
Height (cm) & $173 \pm 10$ \\
Weight $(k g)$ & $85 \pm 17$ \\
\hline Data presented as mean \pm standard deviation or $\mathrm{n}(\%)$. NYHA, New York Heart \\
Association; COPD, chronic obstructive pulmonary disease; BSA, body surface area.
\end{tabular}


TABLE 2. Intraoperative characteristics and operation type

\begin{tabular}{lc}
\hline \multicolumn{1}{c}{ Variable } & Value \\
\hline Aortic operation type & \\
RAA + hemiarch & $13(26)$ \\
Bentall + hemiarch & $12(24)$ \\
RAA + hemiarch + AVR & $15(30)$ \\
Other & $10(20)$ \\
Intraoperative characteristics & \\
Total surgery time (min) & $259 \pm 63$ \\
CPB time (min) & $141 \pm 39$ \\
Crossclamp time (min) & $100 \pm 39$ \\
Circulatory arrest time (min) & $19 \pm 5$ \\
ACP time (min) & $18 \pm 4$ \\
Cooling time (min) & $31 \pm 9$ \\
Nadir nasopharyngeal temperature $\left({ }^{\circ} \mathrm{C}\right)$ & $23 \pm 2$ \\
\hline Da prested as $(\%)$ or m
\end{tabular}

Data presented as $\mathrm{n}(\%)$ or mean \pm standard deviation. $R A A$, Right aortic arch $A V R$, aortic valve replacement; $C P B$, cardiopulmonary bypass; $A C P$, antegrade cerebral protection

We have demonstrated that direct cannulation of the innominate artery is a safe and effective alternative to axillary cannulation for delivering ACP. The options for ACP delivery by way of the innominate artery include direct cannulation or anastomosing a vascular graft to the artery. Preventza and colleagues ${ }^{14}$ demonstrated successful innominate artery perfusion with an $8-\mathrm{mm}$ Dacron side graft in 68 patients. Our technique avoids both partial clamping of the artery and the additional step of sewing a side graft to the innominate artery, as described by Preventza and colleagues. ${ }^{14}$ The $14 \mathrm{~F}$ cannula we used was chosen because it can be introduced over a wire, facilitating safe introduction into the artery, the side holes allow for gentle dispersion of the perfusate without causing damage to the vessel wall, and the caliber is sufficient to achieve the desired perfusion pressure and flow $(>1 \mathrm{~L} / \mathrm{min})$.

In 2000, Banbury and Cosgrove ${ }^{15}$ reported their experience of direct innominate artery cannulation with a $24 \mathrm{~F}$ cannula in a series of 20 patients. Hokenek and colleagues ${ }^{16}$ similarly described their experience with direct innominate artery cannulation with a large $22 \mathrm{~F}$ to $24 \mathrm{~F}$ arterial cannula. Just as with our technique, both investigative groups found that it eliminated the need to attach a 8 -mm side graft. ${ }^{15,16}$ An important distinction between our method and that reported by Banbury and Cosgrove ${ }^{15}$ and Hokenek and colleagues, ${ }^{16}$ relates to the size of the cannula used. The size of the base of the innominate artery varies from relatively normal $(10-15 \mathrm{~mm})$ to moderately dilated or aneurysmal $(\leq 50 \mathrm{~mm}){ }^{17,18}$ Introducing a large cannula, such as a $22 \mathrm{~F}$ to $24 \mathrm{~F}$ arterial cannula, has the potential to injure the back wall of the artery; thus, many patients with a normal size innominate artery might not qualify for direct cannulation with a large cannula. Furthermore, the use of a large $24 \mathrm{~F}$ cannula requires rotating the cannula several times to alternate between whole body perfusion and delivery of $\mathrm{ACP}$, further increasing the risk of vascular injury and potentially creating emboli. Our use of a smaller $14 \mathrm{~F}$ cannula, instead of a $24 \mathrm{~F}$ cannula, decreased the risk of trauma to the innominate artery by minimizing the dissection and manipulation of the artery, especially because the cannula is introduced over a flexible J-tipped wire and is not limited by the size of the innominate artery. Thus, our technique can be applied widely to both
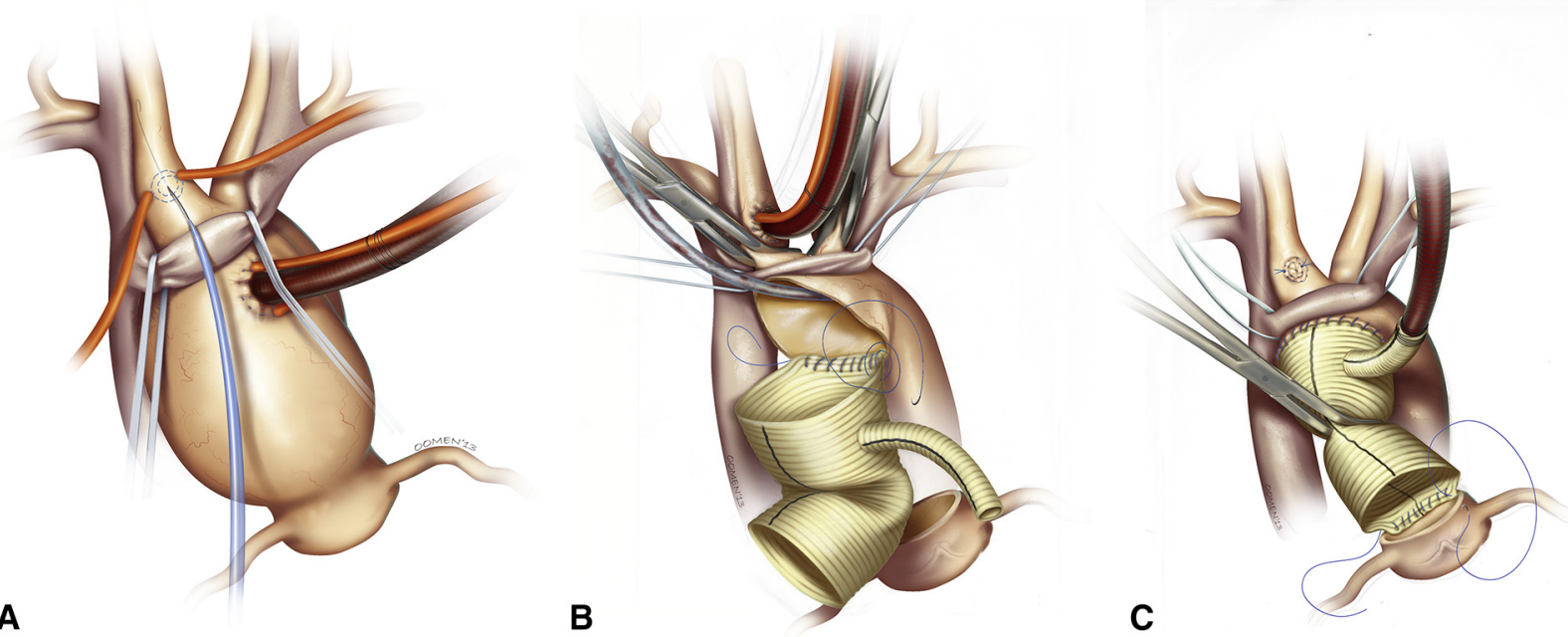

FIGURE 1. Illustration of the surgical technique used in innominate artery cannulation. A, The innominate vein is isolated and retracted and the base of the innominate artery gently mobilized. Two purse-string sutures were placed on the anterior wall of the proximal innominate artery, and dilators and the cannula were inserted over a guidewire. B, Antegrade cerebral protection was initiated by clamping the base of the innominate artery and connecting the afferent limb of the cardiopulmonary bypass circuit to the pediatric venous cannula. C, After the distal anastomosis was completed, antegrade cerebral protection was discontinued, and the aortic line was connected to the 8-mm side limb. The graft was clamped distally and full cardiopulmonary bypass resumed. Proximal reconstruction was performed. 
TABLE 3. Postoperative patient outcomes

\begin{tabular}{lc}
\hline \multicolumn{1}{c}{ Variable } & Value \\
\hline ICU stay (h) & $23 \pm 95$ \\
Ventilation (h) & $9.5 \pm 70$ \\
Postoperative hospital stay (d) & $6 \pm 8$ \\
Survival & $49(98)$ \\
Delirium & $9(18)$ \\
Reoperations & $8(16)$ \\
Postoperative MI & 0 \\
Inotropic support & $27(54)$ \\
Seizure & 0 \\
Postoperative renal failure & $3(6)$ \\
Atrial fibrillation & $16(32)$ \\
Postoperative stroke & $1(2)$ \\
Required RBC transfusion & $18(36)$ \\
Sepsis & $1(2)$ \\
Pulmonary complication & $5(10)$ \\
\hline
\end{tabular}

Data presented as median \pm standard deviation or $\mathrm{n}(\%) . I C U$, Intensive care unit; $M I$, myocardial infarction; $R B C$, red blood cell.

small and large innominate arteries in patients of all body sizes. The 14F cannula was used exclusively for ACP delivery and not for whole body perfusion.

We would caution against the use of our technique in patients with a highly tortuous innominate artery (Figure 2). These patients are uncommon; however, in 2 patients, we encountered excessive resistance when dilating the artery or attempting to place the cannula, and the attempts were aborted. However, neither patient experienced a local or neurologic complication. As a result of this experience, we carefully assess the anatomy of the innominate artery when planning our operative approach. If the artery is deemed highly tortuous, we cannulate the axillary artery. With increased experience, we have safely cannulated

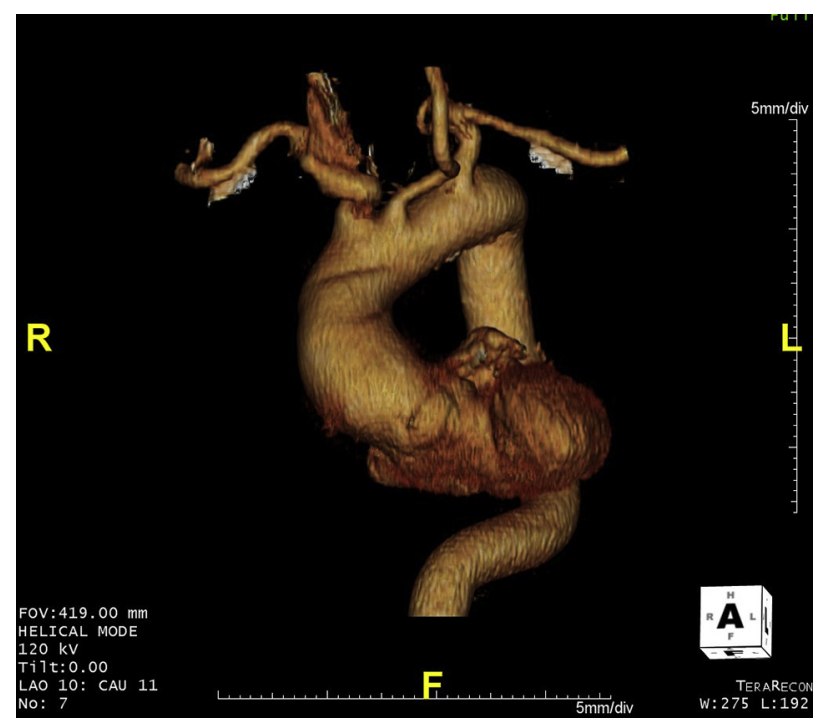

FIGURE 2. Computed tomographic image demonstrating a tortuous innominate artery. several tortuous innominate arteries in cases in which the innominate artery takes a right angle turn shortly after the origin off the aortic arch, by cannulating the straight portion above the acute angle.

Our technique has a number of potential advantages over other methods of ACP delivery: the technique is simple, reproducible, and rapid and avoids the potential complications associated with axillary cannulation. Furthermore, our technique allows delivery of ACP with good outcomes, including low stroke, delirium, and mortality rates. Direct innominate cannulation is now our standard technique for ACP delivery for elective aortic procedures with an anticipated modest duration of circulatory arrest. We do not use this strategy for planned total arch reconstructions, urgent aortic procedures such as repair of type A dissection, or patients with atherosclerosis or severe tortuosity of the innominate artery. Agoustides and colleageus ${ }^{19}$ reported cannulating the innominate artery directly in a single patient with both acute type A dissection and severe atheroma of the descending thoracic aorta. This case report has provided evidence that cannulating the innominate artery during repair for type A dissection is feasible; however, the limited experience does not provide evidence regarding the overall safety of this strategy or the risk of innominate injury or dissection. We avoided cannulating the innominate artery during repair of type A dissection for several reasons. Our technique relies on cannulating the ascending aorta or proximal arch to initiate bypass, which we do not advocate in the setting of acute type A dissection, and we were concerned that manipulating or cannulating a potentially dissected innominate artery could lead to inadvertent false lumen perfusion and, thus, cerebral malperfusion, or propagation of the dissection distally. Although we have not used vascular ultrasound to examine innominate arteries with evidence of dissection or atheroma on preoperative computed tomography imaging, ultrasound scanning might allow for cannulation of the innominate artery in select cases.

\section{CONCLUSIONS}

Selection of the ideal site for cannulation and ACP delivery during aortic surgery must account for the extent of aortic arch reconstruction, ease of use, and minimize the potential for both local arterial and neurologic complications. Direct cannulation of the innominate artery using a $14 \mathrm{~F}$ pediatric venous cannula is a simple, reproducible, safe, and effective technique for establishing ACP in patients undergoing aortic surgery requiring an open distal anastomosis or hemiarch replacement.

\section{References}

1. Svensson LG, Blackstone EH, Rajeswaran J, Sabik JF, Lytle BW, GonzalezStawinski G, et al. Does the arterial cannulation site for circulatory arrest influence stroke risk? Ann Thorac Surg. 2004;78:1274-84. 
2. Sabik JF, Lytle BW, McCarthy PM, Cosgrove DM. Axillary artery: an alternative site of arterial cannulation for patients with extensive aortic and peripheral vascular disease. J Thorac Cardiovasc Surg. 1995;109:885-91.

3. Sabik JF, Nemeh H, Lytle BW, Blackstone EH, Gillinov AM, Rajeswaran J, et al. Cannulation of the axillary artery with a side graft reduces morbidity. Ann Thorac Surg. 2004;77:1315-20.

4. Eusiano MD, Ciano M, Labriola G, Lionetti G, Eusiano GD. Cannulation of the innominate artery during surgery of the thoracic aorta: our experience in 55 patients. Eur J Cardiothorac Surg. 2007;32:270-3.

5. Khaladj N, Shrestha M, Meck S, Peterss S, Kamiya H, Kallenbach K, et al. Hypothermic circulatory arrest with selective antegrade cerebral perfusion in ascending aortic and aortic arch surgery: a risk factor analysis for adverse outcome in 501 patients. J Thorac Cardiovasc Surg. 2008;135:908-14.

6. Bartolomeo RD, Pilato E, Pacini D, Savini C, Eusanio MD. Cerebral protection during surgery of the aortic arch. Multimed Man Cardiothorac Surg [Internet] 2011 Feb 21. Available at: http://mmcts.ctsnetjournals.org/cgi/content/full/ 2011/0221/mmcts.2010.004457. Accessed August 19, 2011.

7. Strauch JT, Speilvogel D, Lauten A, Lansman SL, McMurtry K, Bodian C, et al. Axillary artery cannulation: routine use in ascending aorta and aortic arch replacement. Ann Thorac Surg. 2004;78:103-8.

8. Gulbins H, Pritisanac A, Ennker J. Axillary versus femoral cannulation for aortic surgery: enough evidence for a general recommendation? Ann Thorac Surg. 2007:83:1219-24.

9. Apostolakis E, Koletsis EN, Dedeilias P, Kokotsakis JN, Sakellaropoulos G, Psevdi A, et al. Antegrade versus retrograde cerebral perfusion in relation to post-operative complications following aortic arch surgery for acute aortic dissection type A. J Card Surg. 2008;23:480-7.

10. Strauch JT, Speilvogel D, Lauten A, Lansman SL, McMurtry K, Bodian C, et al. Axillary artery cannulation: routine use in ascending aorta and aortic arch replacement. Ann Thorac Surg. 2004;78:103-8.

11. Dias RR, Silva IA, Fiorelli AI, Stolf NA. Cerebral protection: sites of arterial cannulation and brain perfusion routes. Braz J Cardiovasc Surg. 2007; 22:235-40.

12. Bachet J, Guilmet D, Goudot B, Dreyfus GD, Delentdecker P, Brodaty D, et al. Antegrade cerebral perfusion with cold blood: a 13-year experience. Ann Thorac Surg. 1999;67:1874-8.
13. Halkos ME, Kerendi F, Myung R, Kilgo P, Puskas JD, Chen EP. Selective antegrade cerebral perfusion via right axillary artery cannulation reduces morbidity and mortality after proximal aortic surgery. J Thorac Cardiovasc Surg. 2009;138:1081-9.

14. Preventza O, Bakaeen FG, Stephens EH, Trocciola SM, de la Cruz KI, Coselli JS. Innominate artery cannulation: an alternative to femoral or axillary cannulation for arterial inflow in proximal aortic surgery. J Thorac Cardiovasc Surg. 2013; 145:S191-6.

15. Banbury MK, Cosgrove DM II. Arterial cannulation of the innominate artery Ann Thorac Surg. 2000;69:957.

16. Hokenek AF, Kinoglu B, Gursoy M, Sirin G, Gulcan F. Direct innominate artery cannulation in surgery for annuloaortic ectasia. J Card Surg. 2013;28:550-3.

17. Bachet JE. Distal anastomosis first: the traditional approach. In: Coselli JS, LeMaire SA, eds. Aortic Arch Surgery: Principles, Strategies and Outcomes. 1st ed. Chichester: Blackwell Publishing; 2008:188-98.

18. Mori H, Okamura Y, Mochizuki Y, Iida H, Yamada Y, Eda K, et al. A surgical case of concomitant aneurysms of the brachiocephalic and coronary arteries. Ann Thorac Cardiovasc Surg. 2005;11:128-31.

19. Agoustides JGT, Harris H, Pochettino A. Direct innominate artery cannulation in acute type a dissection and severe thoracic aortic atheroma. J Cardiothorac Vasc Anesth. 2007;21:727-9.

\section{Discussion}

Dr Bansi Koul (Lund, Sweden). An excellent study and preliminary results. However, I wonder, when you have a $14 \mathrm{~F}$ cannula in the innominate, how did you control the blood pressure in these patients before you went on to antegrade cerebral perfusion? Did you cross-check the blood pressure from the left radial and compare that with the right? How did your flows affect the pressures?

Dr Garg. Thank you for your question. We monitored the blood pressure in the contralateral limb, the brachial pressure that way. Also, we did not want to be overperfusing the brain, so we tried to keep our pressures $<70 \mathrm{~mm} \mathrm{Hg}$.

\title{
EDITORIAL COMMENTARY
}

\section{Innominate artery cannulation: The Toronto technique for antegrade cerebral perfusion in aortic arch reconstruction-a clinical trial opportunity for the International Aortic Arch Surgery Study Group}

\author{
John G. Augoustides, MD, FASE, FAHA, ${ }^{\mathrm{a}}$ Nimesh D. Desai, MD, ${ }^{\mathrm{b}}$ Wilson Y. Szeto, MD, ${ }^{\mathrm{b}}$ and \\ Joseph E. Bavaria, MD $^{\mathrm{b}}$
}

\footnotetext{
From the Cardiovascular and Thoracic Section, ${ }^{\mathrm{a}}$ Department of Anesthesiology and Critical Care, and the Division of Cardiac Surgery, ${ }^{\mathrm{b}}$ Department of Surgery, Perelman School of Medicine, University of Pennsylvania, Philadelphia, Pa.

Disclosures: Authors have nothing to disclose with regard to commercial support.

Received for publication Sept 28, 2014; accepted for publication Oct 1, 2014

Address for reprints: John G. Augoustides, MD, FASE, FAHA, Anesthesiology and Critical Care, Dulles 680, HUP, 3400 Spruce St, Philadelphia, PA 19104-4283 (E-mail: yiandoc@ hotmail.com).

J Thorac Cardiovasc Surg 2014;148:2924-6

$0022-5223 / \$ 36.00$

Copyright (c) 2014 by The American Association for Thoracic Surgery

http://dx.doi.org/10.1016/j.jtcvs.2014.10.009
}

See related article on pages $2920-4$.

Antegrade cerebral perfusion (ACP) with hypothermic circulatory arrest (HCA) has recently become a mainstream technique in aortic arch surgery, obviating the requirement for profound hypothermia. ${ }^{1-3}$ Furthermore, extensive recent data demonstrate that unilateral ACP with adequate pressure and monitoring during $\mathrm{HCA}$ has achieved excellent outcomes, suggesting that bilateral ACP may 